OPEN ACCESS

Edited by:

Yann Lamarre,

University of São Paulo, Brazil

Reviewed by:

Nina Claudia Hauck-Weber, University of Amsterdam, Netherlands Vincenza Dolo,

University of L'Aquila, Italy

*Correspondence:

Ana Merino

a.merinorodriguez@erasmusmc.nl

Specialty section: This article was submitted to Immunological Tolerance and Regulation,

a section of the journal

Frontiers in Immunology

Received: 07 January 2021 Accepted: 19 March 2021 Published: 07 April 2021

Citation:

Merino A, Sablik M, Korevaar SS, López-Iglesias C, Ortiz-Virumbrales M,

Baan CC, Lombardo E and Hoogduijn MJ (2021) Membrane Particles Derived From Adipose Tissue Mesenchymal Stromal Cells Improve Endothelial Cell Barrier Integrity.

Front. Immunol. 12:650522. doi: 10.3389/fimmu.2021.650522

\section{Membrane Particles Derived From Adipose Tissue Mesenchymal Stromal Cells Improve Endothelial Cell Barrier Integrity}

\author{
Ana Merino ${ }^{1 *}$, Marta Sablik ${ }^{1}$, Sander S. Korevaar ${ }^{1}$, Carmen López-Iglesias ${ }^{2}$, \\ Maitane Ortiz-Virumbrales ${ }^{3}$, Carla C. Baan ${ }^{1}$, Eleuterio Lombardo ${ }^{3}$ \\ and Martin J. Hoogduijn ${ }^{1}$

\begin{abstract}
${ }_{1}^{1}$ Nephrology and Transplantation, Department of Internal Medicine, Erasmus Medical Center, Rotterdam, Netherlands, ${ }^{2}$ Microscopy CORE Lab, Maastricht Multimodal Molecular Imaging Institute, FHML Maastricht University, Maastricht, Netherlands, ${ }^{3}$ Takeda Madrid, Cell Therapy Technology Center, Madrid, Spain
\end{abstract}

Proinflammatory stimuli lead to endothelial injury, which results in pathologies such as cardiovascular diseases, autoimmune diseases, and contributes to alloimmune responses after organ transplantation. Both mesenchymal stromal cells (MSC) and the extracellular vesicles (EV) released by them are widely studied as regenerative therapy for the endothelium. However, for therapeutic application, the manipulation of living MSC and large-scale production of EV are major challenges. Membrane particles (MP) generated from MSC may be an alternative to the use of whole MSC or EV. MP are nanovesicles artificially generated from the membranes of MSC and possess some of the therapeutic properties of MSC. In the present study we investigated whether MP conserve the beneficial MSC effects on endothelial cell repair processes under inflammatory conditions. MP were generated by hypotonic shock and extrusion of MSC membranes. The average size of MP was $120 \mathrm{~nm}$, and they showed a spherical shape. The effects of two ratios of MP (50,000; 100,000 MP per target cell) on human umbilical vein endothelial cells (HUVEC) were tested in a model of inflammation induced by TNF $\alpha$. Confocal microscopy and flow cytometry showed that within 24 hours $>90 \%$ of HUVEC had taken up MP. Moreover, MP ended up in the lysosomes of the HUVEC. In a co-culture system of monocytes and TNF $\alpha$ activated HUVEC, MP did not affect monocyte adherence to HUVEC, but reduced the transmigration of monocytes across the endothelial layer from $138 \pm 61$ monocytes per microscopic field in TNF $\alpha$ activated HUVEC to $61 \pm 45$ monocytes. TNF $\alpha$ stimulation induced a 2 -fold increase in the permeability of the HUVEC monolayer measured by the translocation of FITC-dextran to the lower compartment of a transwell system. At a dose of 1:100,000 MP significantly decreased endothelial permeability (1.5-fold) respect to TNF $\alpha$ Stimulated HUVEC. Finally, MP enhanced the angiogenic potential of HUVEC in an in vitro Matrigel assay by stimulating the formation of angiogenic structures, such as percentage of covered area, total tube length, total branching points, total loops. In conclusion, MP show regenerative 
effects on endothelial cells, opening a new avenue for treatment of vascular diseases where inflammatory processes damage the endothelium.

Keywords: membrane particles, nanovesicles, mesenchymal stromal cells, endothelial cells, regeneration, immune cell interaction

\section{INTRODUCTION}

The endothelium forms an interactive barrier between the circulatory system and the tissues in the body. It plays a pivotal role in the regulation of vascular permeability, hemostasis, and immunological processes (1). Alterations of endothelial cells (EC) play a central role in the pathogenesis of a broad spectrum of the most dreadful of human diseases, such as atherosclerosis (2), stroke (3), heart disease (4), diabetes (5), allograft rejection (6), and chronic kidney failure (7). Inflammatory mediators cause overexpression of cell adhesion molecules (CAM) on EC and together with the secretion of cytokines this permits the attraction and adhesion of circulating immune cells to the endothelium, and consequently, the transmigration of leukocytes into inflammation sites (8). Therapies that protect the endothelium from stress and immune factors or enhance the repair processes may be capable of curing or preventing diseases where the endothelium has a key role.

Mesenchymal stromal cells (MSC) represent such therapy as they have immunomodulatory and regenerative capacities and are known to deliver endothelial protective signals (9). The endothelial protective effects of MSC are due to their antiinflammatory and repair properties that have shown substantial therapeutic promise in preclinical models, such as for instance in atherosclerosis (10). Moreover, MSC hold great promise for revascularization of tissues as they secrete proangiogenic and anti-apoptotic factors in large amounts (11).

The translation of the endothelial protective and reparative effects of MSC found in the in vitro setting to an effective therapy is hampered by the poor biodistribution of infused MSC after intravenous administration. It is demonstrated that after intravenous infusion, MSC get trapped in the lungs and have a short survival time $(12,13)$. This implies that MSC do not reach sites of injury and cannot interact locally with injured tissue. Viable MSC may secrete cytokines and growth factors in the circulation and target distant cells via this route, but recent work demonstrated that inactivated MSC, which lost their capacity to secrete factors, maintain their immunomodulatory capacity in an animal model (14), suggesting that cell membrane dependent interactions with target cells play a role in the immune regulatory effects of MSC. Furthermore, MSC-conditioned media have shown to possess similar regenerative properties as MSC on tissue damage and contribute to the modulation of inflammation (15). Conditioned medium is composed of growth factors, cytokines, and extracellular vesicles (EV). EV are spherical membrane fragments heterogeneous in size and composition that carry and transfer proteins, lipids, and RNA from the source cells to resident cells in damaged tissue (16). MSC-derived EV have shown therapeutic effects in several diseases' models including CVD (17) and acute kidney injury (18). Despite EV may be a promising alternative cell-free therapy, clinical translation is hindered by the lack of suitable and scalable technologies for the generation and purification of extracellular vesicles $(19,20)$. Thus, novel methods are needed to make pharmaceutically controllable and homogeneous membrane vesicles for targeting injured tissues.

We previously reported on the generation of large amounts of membrane particles (MP) from human adipose tissue MSC (ATMSC) (21). The size of these man-made MP was with on average $120 \mathrm{~nm}$, like naturally occurring EV, and electron microscopy showed they have a spherical shape. MP were shown to be able to modulate immune cells, thereby showing a great potential as a novel cell-free immune therapy, and a good alternative to EV therapy as MP can be produced in large amounts, highly purified, in an easy and economic process.

In the present study, we have investigated the potential therapeutic effects of MP derived from AT-MSC on the barrier integrity of inflamed endothelial cells using a model of TNF $\alpha$ treated human umbilical vein endothelial cells (HUVEC). We further explored whether MP could enhance the angiogenic ability of HUVEC in an inflammatory environment.

\section{MATERIAL AND METHODS}

\section{Ethics Statement and Human Tissue Samples}

Human MSC were isolated from subcutaneous adipose tissue from healthy kidney donors that became available during kidney donation procedures. The tissues were collected after obtaining written informed consent, as approved by the Medical Ethical Committee of the Erasmus University Medical Centre Rotterdam (protocol no. MEC-2006-190).

\section{Isolation and Culture of MSC From Adipose Tissue}

AT-MSC were isolated from subcutaneous adipose tissue of five healthy donors ( 2 females/3 males). The age of the donors was between $34-58$ years old. The tissue was mechanically disrupted and enzymatically digested with $0.5 \mathrm{mg} / \mathrm{ml}$ collagenase type IV (Sigma-Aldrich, St. Louis, MO) in RPMI for $30 \mathrm{~min}$ at $37^{\circ} \mathrm{C}$ under continuous shaking. Thereafter, the cells were resuspended in MEM- $\alpha$ with $10 \%$ fetal bovine serum (FBS; Lonza, Verviers, Belgium), $2 \mathrm{mM}$ L-glutamine and $1 \% \mathrm{P} / \mathrm{S}$, filtered through a $100 \mu \mathrm{m}$ cell strainer, and transferred to 175 $\mathrm{cm}^{2}$ culture flasks (Greiner Bio-one, Essen, Germany). At 90\% confluence AT-MSC (passage 2-6) were collected to generate MP. The phenotypic characterization of AT-MSC was performed 
by flow cytometry using FACSCANTO-II with FACSDIVA Software (BD Biosciences, San Jose, CA). AT-MSC were incubated with mouse-anti-human monoclonal antibodies against CD13-PE-Cy7; HLA-DR-PERCP; HLA-ABC-APC; CD31-FITC; CD73-PE; PD-L1-PE (all BD Biosciences); CD90APC and CD105-FITC (R\&D Systems, Abingdon, UK). All the antibodies were incubated with the cells for $30 \mathrm{~min}$, at room temperature in the absence of light.

\section{Culture of Human Umbilical Vein Endothelial Cells}

First-passage cryopreserved HUVEC from pooled donors were obtained from Promocell (Promocell, Germany). HUVEC were grown in $75 \mathrm{~cm}^{2}$ flasks at $37{ }^{\circ} \mathrm{C}, 5 \% \mathrm{CO}_{2}$ with endothelial cell basal medium (EBM, Cambrex Bio Science Walkersville, Inc., Walkersville, MD, USA), endothelial cell growth medium supplements (EGM, Cambrex Bio Science), 10\% FBS, $100 \mathrm{IU} / \mathrm{mL}$ penicillin, and $100 \mathrm{mg} / \mathrm{mL}$ streptomycin. At $90 \%$ confluence, HUVEC were dissociated by $0.05 \%$ trypsin-EDTA (Life Technologies, Bleiswijk, The Netherlands). To establish an endothelial cell model of inflammation, HUVEC were incubated with TNF $\alpha(25 \mathrm{ng} / \mathrm{ml})$ for $4 \mathrm{~h}$ or $24 \mathrm{~h}$ depending on the assay. All HUVEC used in the experiments were between passage 2-7. During these passages, HUVEC conserved their morphology, phenotype, and proliferation rate. For the stimulation of HUVEC with TNF $\alpha$, three concentrations of TNF $\alpha$ were tested $(10,25,50 \mathrm{ng} / \mathrm{ml})$. All the experiments were performed with the concentration $25 \mathrm{ng} / \mathrm{ml}$ due to the difference respect to adhesion molecules and monocyte adhesion assay between Control and TNF $\alpha$ treated cells was enough to allow MP play a role, without inducing HUVEC apoptosis.

\section{Generation of Membrane Particles From AT-MSC}

AT-MSC were trypsinized and washed twice with PBS. Then, the MSC were incubated in milliQ water at $4^{\circ} \mathrm{C}$ to induce osmotic lysis and liberation of the cell nuclei (after about $20 \mathrm{~min}$, monitored by microscope). Cell extracts were cleared of unbroken cells and nuclei by centrifugation at 2,000 x $g$ for
$20 \mathrm{~min}$. The obtained supernatant was transferred to Amicon Ultra-15 filter tubes (100 $\mathrm{kDa}$ pore size) and concentrated by centrifugation at $4,000 \times \mathrm{g}$ at $4^{\circ} \mathrm{C}$. The concentrated pellet consisted of crude membrane and was diluted in $0.2 \mu \mathrm{m}$ filtered PBS. A population of MP, homogeneous in size was obtained by extruding the plasma membranes 3 times through polycarbonate membrane filters (Merck, KGaA, Darmstadt, Germany), first with a pore diameter of $800 \mathrm{~nm}$, secondly with a $400 \mathrm{~nm}$ and last with a $200 \mathrm{~nm}$ pore size filter. The extrusion process was performed using LiposoFast LF-50 (AVESTIN Europe, Mannheim, Germany) at 20 psi (Figure 1). All procedures were performed on ice.

\section{Analysis of Adhesion Markers on HUVEC}

HUVEC were incubated with TNF $\alpha(25 \mathrm{ng} / \mathrm{ml})$ and two ratios of MP (1:50,000, 1:100,000 HUVEC : MP) during 24h. Then, the cells were trypsinized and washed with FACS Flow (BD Biosciences, San Jose, CA). The immunophenotypic characterization of the activation state of endothelial cells was done by incubating HUVEC with mouse-anti-human monoclonal antibodies against CD54-APC, CD106-BV421, CD62e-PE, CD31-FITC, VEGFR2-PE, CD105-FITC and TIE2Alex647 (all BD Biosciences). All the antibodies were incubated with the cells for $30 \mathrm{~min}$, at room temperature in the absence of light. After two washes with FACS Flow, flow cytometric analysis was performed using FACSCANTO-II with FACSDIVA Software (BD Biosciences).

\section{Characterization of MP Size and Concentration by Nanoparticle Tracking Analysis}

Analysis of absolute size distribution and concentration of MP was performed using NanoSight NS300 (NanoSight Ltd.). With NTA, particles are automatically tracked and sized based on Brownian motion and the diffusion coefficient. The NTA measurement conditions were: detection threshold 3 (determined with a protein solution), three measurements per sample (30 s/ measurement), temperature $23.61 \pm 0.8^{\circ} \mathrm{C}$; viscosity $0.92 \pm 0.02$ $\mathrm{cP}$, frames per second 25 . Each video was analyzed to give the

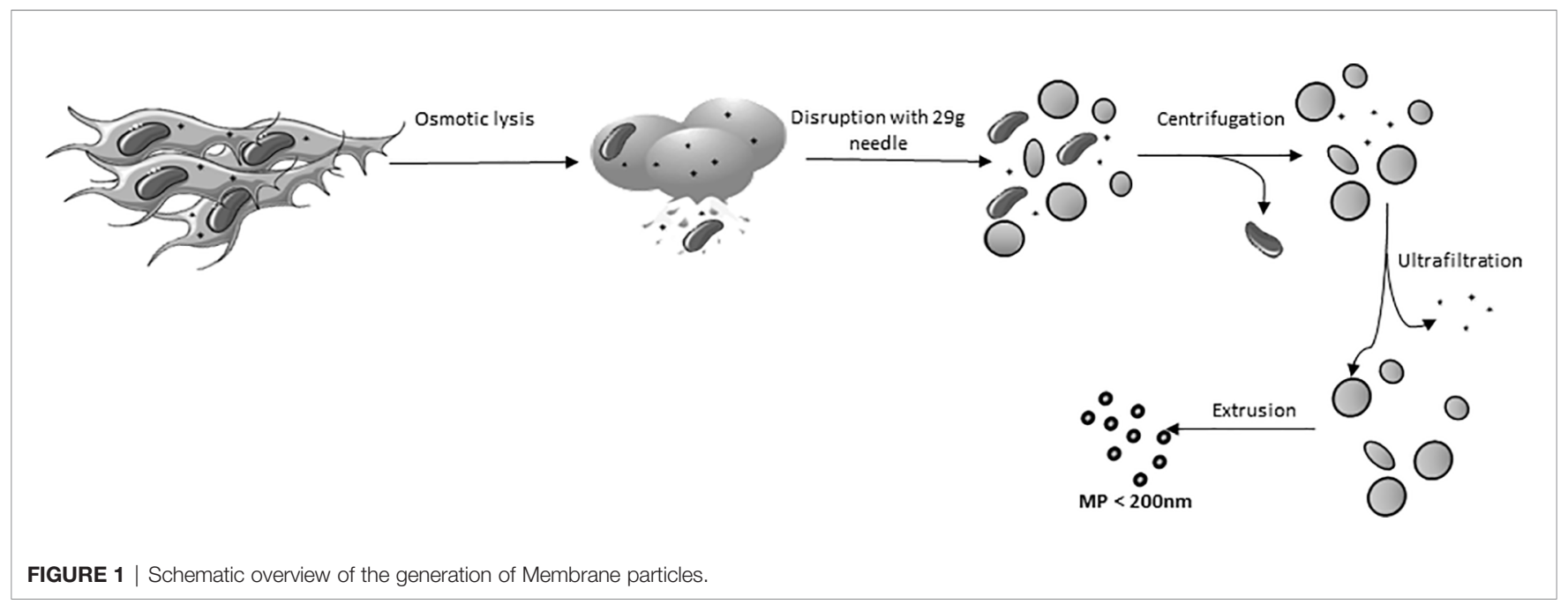


mean, mode, median and estimated concentration for each particle size. The samples were diluted in $0.2 \mu \mathrm{m}$ filtered PBS, to obtain a measurable concentration of particles $\left(1 \times 10^{8}\right.$ particles $\left./ \mathrm{ml}\right)$ in accordance with the manufacturer's recommendations.

\section{Cryo-Transmission Electron Microscopy}

The preparations of MP were visualized by the Cryo-TEM method. A thin aqueous film was formed by applying a $3 \mu \mathrm{l}$ droplet of MP suspension to a specimen bare EM grid. Glowdischarged holey carbon grids were used. After the application of the suspension the grid was blotted against filter paper, leaving a thin sample film spanning the grid holes. These films were vitrified by plunging the grid into ethane, which was kept at its melting point by liquid nitrogen, using a Vitrobot (Thermo Fisher Scientific Company, Eindhoven, The Netherlands). The vitreous sample films were transferred to a Tecnai Arctica microscope (Thermo Fisher Scientific, Eindhoven, The Netherlands). Images were taken at $200 \mathrm{Kv}$ with a field emission gun using a Falcon III (Thermo Fisher Scientific) direct electron detector.

\section{Extraction and Identification of DNA/RNA From MP}

To examine whether DNA and RNA are present in MP, a High Pure RNA Isolation Kit (Roche Applied Science, Penzberg, Germany) was used to extract DNA/RNA from MP samples following the manufacturer's instructions. After the isolation of the RNA/DNA, the samples were treated with DNase I to quantify the concentration of RNA, whereas for the collection of both DNA and RNA, DNase I treatment was omitted. The concentration and purity of DNA+RNA and RNA in the samples was assessed spectrophotometrically using a NanoDrop ND1000 (Thermo Fisher Scientific, Bleiswijk, The Netherlands). The quality of the RNA was assessed by assigning an RNA integrity number (RIN) using an Agilent 2100 Bioanalyzer (Agilent Technologies, Santa Clara, CA, USA).

\section{Quantitative RT-PCR Analysis}

MP were stored at $-80^{\circ} \mathrm{C}$. Total RNA was isolated, and $500 \mathrm{ng}$ used for complementary DNA (cDNA) synthesis. Gene expression was determined by Quantitative Real-Time PCR (qPCR) using the TaqMan Universal PCR Master Mix (Life Technologies ThermoFisher scientific), and the assay-ondemand primer/probes for Thermo Fisher GAPDH (Hs99999905.m1); CD90 (Hs00264235_s1), Vascular endothelial growth factor A (VEGF-A: Hs00173626.m1), Angiopoietin 1 (Hs01586213.m1), IL-8 (Hs00174114.m1). For PCR, cDNA synthesized from $25 \mathrm{ng}$ total RNA was used to perform each amplification.

\section{Assessment of MP Toxicity on HUVEC: Apoptosis Assay}

HUVEC were seeded at a density of $2 \times 10^{5} /$ well in 12 -well plates. Then, unstimulated and TNF $\alpha(25 \mathrm{ng} / \mathrm{ml})$ stimulated HUVEC were cultured with 2 ratios of MP (HUVEC : MP 1:50,000, 1:100,000) during $24 \mathrm{~h}$ and $48 \mathrm{~h}$. Cell viability was assessed using an Annexin $\mathrm{V}$ staining kit (BD Biosciences) according to the manufacturer's recommendations. Briefly, after the incubation time with MP, cells were harvested, washed in PBS, and resuspended in a binding buffer that contained $5 \mu$ l Annexin V antibody and $5 \mu \mathrm{l}$ 7-AAD. Samples were measured by FACSCanto II (BD Biosciences).

\section{Uptake of MP by HUVEC}

AT-MSC were labeled with red fluorescent PKH-26 dye, which intercalates into lipid bilayers, according to the manufacturer's instructions (Sigma-Aldrich), enabling the generation of fluorescent MP (PKH-MP). HUVEC were plated at a density of $2 \times 10^{5}$ cells/well on a 12 well plate, treated with/without TNF $\alpha$ (25ng/mL). Two ratios of PKH-MP, (1:50,000 and 1:100,000) were added to the cultures for $4 \mathrm{~h}$ and $24 \mathrm{~h}$ and the uptake of MP by HUVEC was quantified by flow cytometry. The data were analyzed using Kaluza Software (Beckman Coulter).

For confocal microscopy analysis, cell membranes of HUVEC were labeled with $\mathrm{PKH}-67$, the nuclei with $10 \mu \mathrm{M}$ Hoechst 33342, and the lysosomes with a LysoSensor dye (Invitrogen Molecular Probes), which changes to yellow fluorescence in acidic environments. PKH-MP uptake by HUVEC was imaged by a Leica TCS SP5 confocal microscope (Leica Microsystems B.V., Science Park Eindhoven, Netherlands), equipped with Leica Application Suite - Advanced Fluorescence (LAS AF) software, DPSS $561 \mathrm{~nm}$ lasers, using a $40 \mathrm{X}$ (1.4 NA oil) objective. Microscopic images were processed using ImageJ 1.48 (National Institutes of Health, Washington, USA).

\section{Monocyte Adhesion Assay}

HUVEC were seeded at $0.5 \times 10^{6}$ cells/well in a 12 well plate and TNF $\alpha$ added at $25 \mathrm{ng} / \mathrm{mL}$ for $24 \mathrm{~h}$ in combination with MP at a ratio of 1:50,000. Peripheral blood mononuclear cells (PBMC) were isolated from a buffy coat of healthy individuals. Monocytes were purified from the buffy coat using auto-MACS Pro by negative-selection (Miltenyi Biotec, Germany). The purified monocytes were labeled with $1 \mu \mathrm{M}$ of CFSE and kept in suspension $\left(1 \times 10^{6}\right.$ cells $\left./ \mathrm{mL}\right)$ in culture medium consisting of RPMI 1640 medium (Life Technologies), supplemented with $10 \% \mathrm{FBS}, 100 \mathrm{IU} / \mathrm{mL}$ penicillin and $100 \mathrm{mg} / \mathrm{mL}$ streptomycin. Monocyte purity was checked using flow cytometry after staining with mouse-anti-human monoclonal antibody against CD14 (BD Biosciences) for $20 \mathrm{~min}$ at room temperature. CFSElabeled monocytes ( $1 \times 10^{5}$ per condition) were added to the stimulated HUVEC and incubated for $1 \mathrm{~h}$ at $37^{\circ} \mathrm{C}, 5 \% \mathrm{CO}_{2}$. The incubation time of $1 \mathrm{~h}$ was determined as the time where monocytes in suspension were not anymore observed in the TNF $\alpha$ condition (positive control). After a thorough wash with EBM, the cultures were photographed with a Leica TCS SP5 confocal microscope. Microscopic images were processed using ImageJ 1.48. Stained cells were counted in five randomly selected areas using bright field microscopy $(\times 20)$.

\section{Transwell Cell Transmigration Assay}

HUVEC $\left(1 \times 10^{5}\right.$ cells/transwell) were plated in Transwell ${ }^{\circledR}-24$ well inserts (Costar, Corning Inc.), consisting of polycarbonate filters ( $8 \mu \mathrm{m}$ pore size; $0.33 \mathrm{~cm}^{2}$ area), and grown to confluence for $24 \mathrm{~h}$. HUVEC were then treated with $25 \mathrm{ng} / \mathrm{mL} \mathrm{TNF} \alpha$ and 
50,000 MP per HUVEC for 24h. Then, the supernatant was discarded and the transwells were transferred to a new well containing $500 \mu \mathrm{L}$ of $50 \mathrm{ng} / \mathrm{mL}$ Monocyte Chemoattractant Protein-1 (MCP-1, Invitrogen Molecular Probes) in the lower well. Monocytes were isolated, labeled with $\mathrm{PKH}-26$, and plated in the transwell at a ratio of 2:1 (monocyte:HUVEC). Following 2 hours of incubation at $37^{\circ} \mathrm{C}$ and $5 \% \mathrm{CO}_{2}$, the supernatant of the transwells was carefully removed together with the nonadhering monocytes. The adherent cells were washed twice with PBS and stained with $10 \mu \mathrm{M}$ Hoechst 33342 for $10 \mathrm{~min}$ at $37^{\circ} \mathrm{C}$, $5 \% \mathrm{CO}_{2}$. The inserts were then washed twice with PBS and fixed with $4 \%$ formaldehyde dissolved in PBS for $15 \mathrm{~min}$ at room temperature. Monocytes that migrated through both the HUVEC monolayer and polycarbonate membrane and adhered to the bottom side of the transwell membrane were visualized by Z-stacks analysis using a Leica TCS SP5 confocal microscope. The number of transmigrated monocytes was determined by counting the number of $\mathrm{PKH}-26$ fluorescent monocytes present in 5 randomly selected fields of view per sample via ImageJ 1.48 .

\section{Transwell Permeability Assay}

To analyze the endothelial cell barrier integrity 50,000 HUVEC were grown on a transwell insert pre-coated with fibronectin (polystyrene, 0.4 um pore size; Greiner Bio-one, The Netherlands) until confluency. The monolayers of HUVEC were then treated with $25 \mathrm{ng} / \mathrm{mL}$ TNF $\alpha$ and two ratios of MP $(50,000$ and 100,000 MP : HUVEC) for 24h. After the incubation time, the supernatant was removed and FITC-dextran $(1 \mathrm{mg} / \mathrm{ml} ; 70 \mathrm{kDa}$; Bio-connect, The Netherlands) was added to the transwells. After $2 \mathrm{~h}$, the FITC-dextran translocated to the lower compartment of the transwell was measured in a microplate reader at excitation/ emission wavelength of $490 / 520 \mathrm{~nm}$. As a positive control a transwell without cells was used. By normalizing the fluorescence signals of the treatment group to the control group a measure of endothelial layer leakiness was obtained.

\section{Angiogenesis Assay/Tube Formation Assay}

A confluent monolayer of HUVEC was treated with MP at a ratio of 1:50,000 and treated with/without TNF $\alpha(25 \mathrm{ng} / \mathrm{ml})$ for $24 \mathrm{~h}$. After the incubation time, HUVEC were collected by trypsinization and seeded on $50 \mu$ l polymerized Matrigel (Geltrex, ThermoFisher, USA). The major components of Geltrex $^{\mathrm{TM}}$ matrix include laminin, collagen IV, entactin, and heparin sulfate proteoglycans. The protein concentration is $15 \mathrm{mg} / \mathrm{ml}$. Each condition was plated in duplicate. After $18 \mathrm{~h}$, tube formation was observed and photographed using an inverted light microscope equipped with a digital camera. The percentage of covered area (percentage of tubular structures in the whole area of the image), total tube length (complete length in pixel of the tubular structure), total branching points (a branching point is part of the skeleton where three or more tubes converge), and the number of loop areas (a loop is an area enclosed by tubular structures) were measured by WIMASIS (Onimagin Technologies SCA, Córdoba, Spain).

\section{Sample Size and Statistical Analysis}

In the experiments MP from 5 donors were used in duplicate. For the apoptosis, expression of adhesion markers and monocyte adhesion assays, 5 independent experiments were performed where MP from 2 different donors were tested in each experiment. For the monocyte migration assay, barrier integrity and angiogenesis assays, 3 independent experiments were performed where MP from 3 different donors were tested in each experiment. Data were analyzed for normal distribution by Kolmogorov-Smirnov test, and after that T-Test was used to determine the significance between the groups using GraphPad Prism 5 software. $\mathrm{P}<0.05$ was considered significant.

\section{RESULTS}

\section{Morphology and Size Distribution of MP Generated From AT-MSC}

MP were generated from culture-expanded AT-MSC and characterized by cryo-electron microscopy and NTA to determine their shape, concentration, and size distribution. Cryo-electron microscopy showed that MP have a spherical shape and a discernible lipid bilayer (Figure 2A). Some MP were found encapsulated inside larger MP. The size range of MP was between 32 and $345 \mathrm{~nm}$, with an average peak size frequency of $126.5 \pm 22.4 \mathrm{~nm}$. The frequency of particles larger than $200 \mathrm{~nm}$ (cut-off pore size) was lower than $0.5 \pm 0.3 \%$ (Figure 2B).

\section{Presence of RNA in MP}

To examine whether MP preparations contained DNA and RNA, DNA and RNA concentrations were determined by Nanodrop. MP preparations contained $35.2 \pm 3.9 \mathrm{ng} / \mathrm{ul}$ DNA/RNA (Figure 2C). After DNase treatment, the concentration of DNA/RNA did not change (Figure 2C), suggesting MP contain RNA, but no DNA. To determine whether the RNA could be detected by RTPCR, several genes expressed by MSC were analyzed. PCR product was obtained for GAPDH, the angiogenic genes VEGFA, angiopoietin 1 and FGF-2, IL-8, and for the MSC cell surface marker CD90 (Figure 2D) suggesting that MP preparations contained RNA from the cell source (Figure 2D).

\section{HUVEC Internalize Membrane Particles in a Time Dependent Manner}

Fluorescent MP were generated by labeling the cell membranes of MSC with PKH-26 (PKH-MP). HUVEC were incubated with or without TNF $\alpha$ and with two ratios of PKH-MP (ratio: 1:50,000 or $1: 100,000)$ for $4 \mathrm{~h}$ or $24 \mathrm{~h}$. Non-Stimulated HUVEC showed a significant increase in the internalization of the PKH-MP with increasing MP dose and over time. However, there was not statistical difference in the internalization of PKH-MP in TNF $\alpha$ Stimulated HUVEC between the two tested MP doses, but there was a significant increase over time (Figure 3A). For the ratios 1:50,000 and 1:100,000 the percentage of Non-Stimulated HUVEC positive for $\mathrm{PKH}-\mathrm{MP}$ was $75.2 \pm 6.3 \%$, and $86.8 \pm 7.4 \%$ respectively after $24 \mathrm{~h}$ of incubation, and for TNF $\alpha$ Stimulated 
A

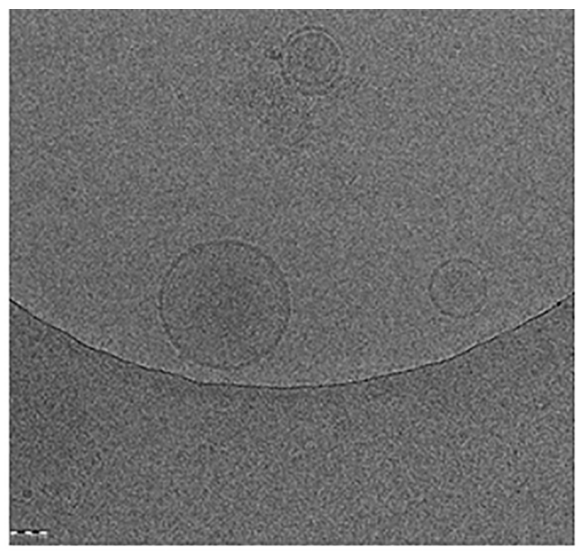

C

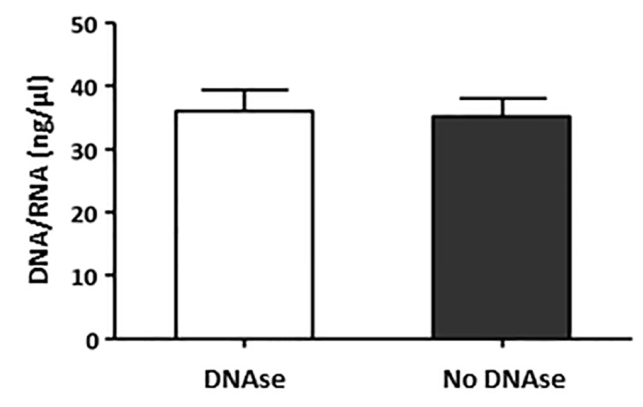

B

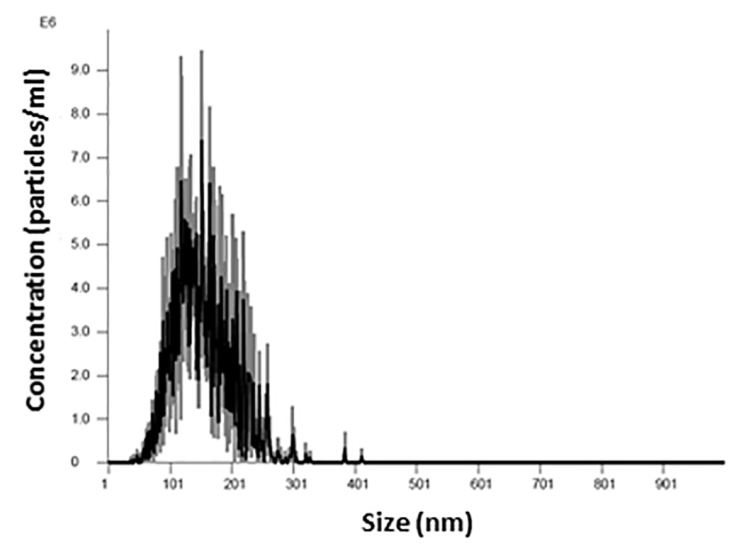

D

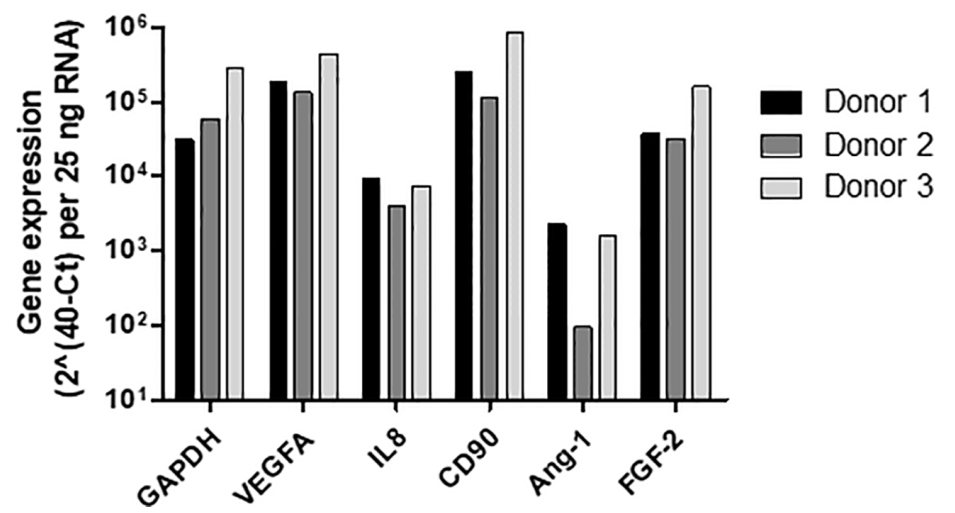

FIGURE 2 | Characterization of physical properties and DNA/RNA composition of membrane particles from MSC. (A) Cryo-electron microscopy images of MP. MP show a spherical shape and a discernible lipid bilayer. (B) A representative profile of the nanoparticle tracking analysis (NTA) of MP. A graph was generated which plots the distribution in size of the MP against the concentration of MP per ml. (C) RNADNA concentration (ng/ $\mathrm{Ml}$ ) in MP samples before and after DNAse treatment. The error bars represent standard deviation of the mean (SD). (D) Relative gene expression of RNA present in MP samples from three different MSC donors.

HUVEC were $82.1 \pm 7.1 \%$, and $82.4 \pm 11.2 \%$. There was not statistical difference between TNF $\alpha$ and Non-Stimulated HUVEC.

The interaction of PKH-MP with HUVEC was visualized using confocal immunofluorescence microscopy. The analysis showed that PKH-MP were internalized and localized in the cytoplasm of HUVEC (Figure 3B). Subsequently, a LysoSensor staining was used to examine whether PKH-MP end up in lysosomes. The LysoSensor staining fluorescently labels endosomes and turns yellow when the $\mathrm{pH}$ in the endosomes is acidic, indicative for lysosomes. After incubating HUVEC with PKH-MP for $24 \mathrm{~h}$, fluorescently labeled MP co-localized with lysosomes (Figure 3C).

\section{Membrane Particles Do Not Induce Apoptosis or Affect the Expression of Adhesion Molecules in HUVEC}

HUVEC were stimulated with TNF $\alpha$ and cultured with two concentrations of MP (1:50,000 and 1:100,000) for $24 \mathrm{~h}$ and $48 \mathrm{~h}$ to determine whether MP induce apoptosis. No increase in apoptosis was observed in non-stimulated and TNF $\alpha$ stimulated HUVEC treated with MP at 24h (Figure 4A) or 48h (Figure 4B).

HUVEC were cultured with MP for $24 \mathrm{~h}$ to determine whether MP could influence adhesion molecules expression (CD54, CD106, CD62e, CD31, CD105) and molecules involved in angiogenesis (VEGFR2, TIE-2) in non-stimulated and TNF $\alpha$ stimulated HUVEC. MP did not modify the expression of ICAM-1 in non-stimulated or TNF $\alpha$-stimulated HUVEC (Figure 4C) or VEGFR2 (Figure 4D). In addition, no changes were observed for the rest of molecules (data not shown).

\section{MP Do Not Affect the Adhesion of Monocytes to HUVEC}

HUVEC were treated with or without TNF $\alpha$ for $24 \mathrm{~h}$ and 1:50,000 MP per HUVEC. Subsequently, the HUVEC were cocultured for $1 \mathrm{~h}$ with CFSE-labeled monocytes to examine the adhesion of monocytes to HUVEC. After washing away nonadherent cells, monocyte adhesion was quantified by analysis of 
A

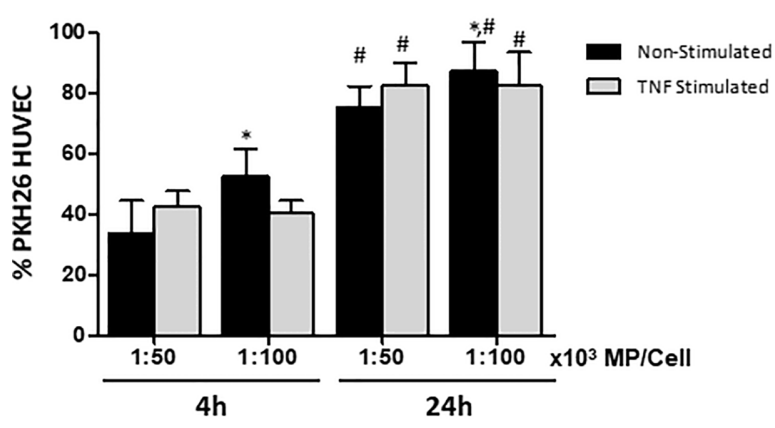

B

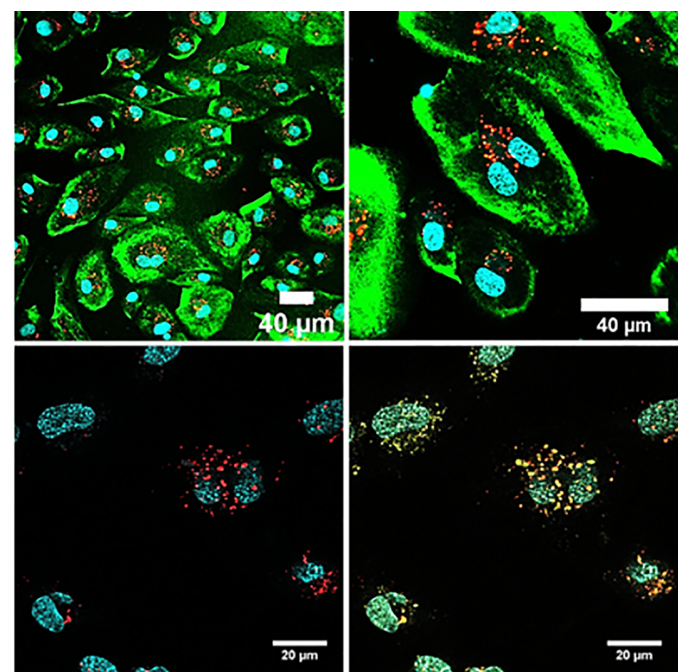

FIGURE 3 | Characterization and quantification of uptake of MP by unstimulated and TNF $\alpha$-stimulated HUVEC. MSC were labeled with PKH-26 before generation of MP (PKH-MP). PKH-MP were added to HUVEC (ratio 1:50,000) and incubated for 4 and $24 \mathrm{~h}$ at $37^{\circ} \mathrm{C}$. (A) Uptake of PKH-MP by unstimulated and TNF $\alpha$-stimulated HUVEC (ratio 1:50,000 and 1:100,000) was quantified using flow cytometry. Uptake is indicated by PKH-MP positive HUVEC (PKH+ HUVEC).

(B) Representative confocal microscopy analysis of PKH-MP uptake by HUVEC at time point 24h. Staining for PKH26-MP (red), PKH-67 cell membrane (green), and Hoechst 33342 nucleus (blue) showed that PKH-MP are internalized by HUVEC. Scale bars: $40 \mu \mathrm{m}$ (C) Staining for PKH-MP (red), lysosomes (yellow) and nucleus (blue) showed that PKH-MP (ratio 1:50,000) are co-localized with lysosomes in HUVEC after 24h of incubation. Scale bars: $20 \mu \mathrm{m}$.

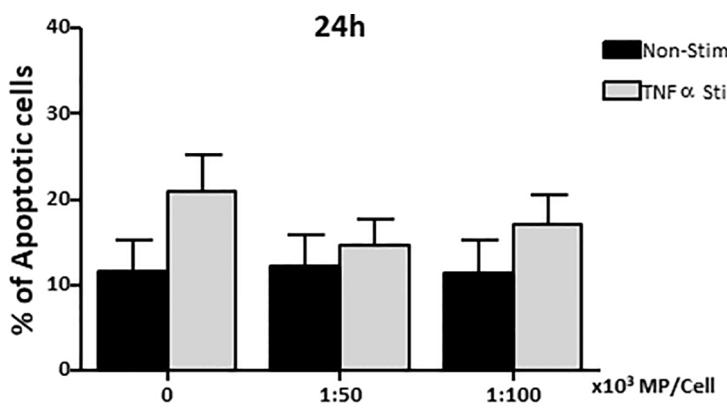

C

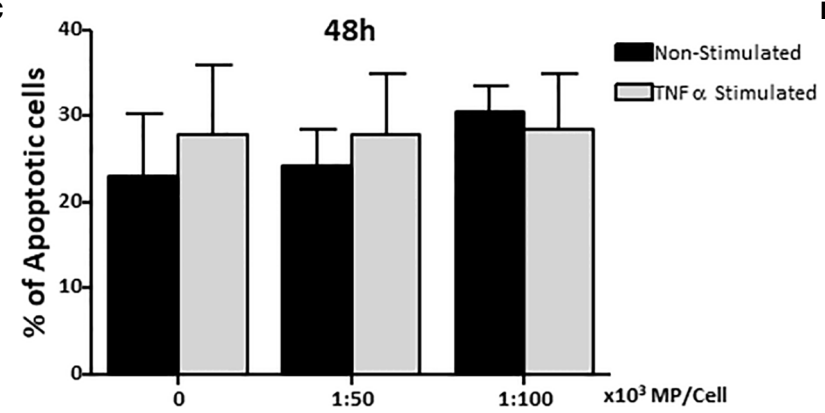

B

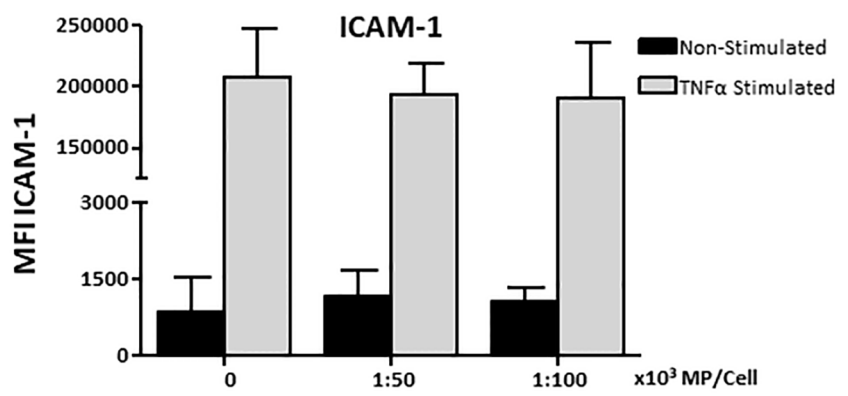

D

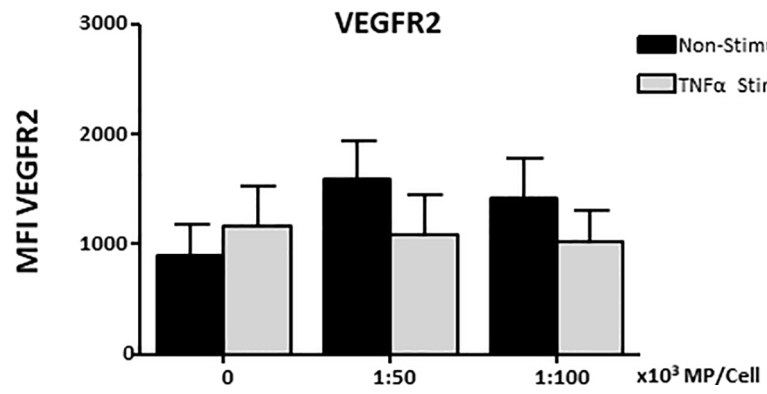

FIGURE 4 | Effect of Membrane Particles on HUVEC apoptosis and adhesion molecules. HUVEC were stimulated with TNF $\alpha$ and treated with two concentration of MP (1:50,000, 1:100,000) and incubated at (A) 24h, and (B) 48h for the analysis of apoptosis. Surface expression of adhesion molecules on HUVEC was measured at the time point of $24 \mathrm{~h}$ (C) ICAM-1, and (D) VEGFR2. Values are means \pm SD of the mean fluorescent intensity of the receptors of 5 independent experiments each testing MP from 2 donors in each experiment. 
confocal microscopy images. Digital images were captured at $\times 20$ magnification and analyzed by Image J software. Figure 5A shows representative images of the studied groups. Activating the HUVEC using TNF $\alpha$ significantly increased the number of monocytes adhering to the HUVEC compared to non-stimulated HUVEC (Figure 5B). There was no effect of MP on the adhesion of monocytes to Non-Stimulated and TNF $\alpha$ Stimulated HUVEC.

\section{Inhibition of Monocyte Transendothelial Migration by Membrane Particles}

To examine the effect of MP on the transendothelial migration potential of monocytes, a HUVEC monolayer on a transwell membrane was treated with TNF $\alpha$ and/or MP and after $24 \mathrm{~h}$ fluorescent monocytes were added (Figure 6A). Monocyte transmigration across the endothelial layer was observed at $2 \mathrm{~h}$. Representative confocal microscopy pictures of the assay are shown in Figure 6B. Addition of the chemo-attractant (MCP-1) to the lower well significantly increased the number of migrated monocytes 2.3-fold compared to PBS (PBS: $59.7 \pm 24.3$; MCP-1: $138.2 \pm 61$ migrated monocytes per microscopic field). MP were able to significantly reduce the number of monocytes that migrated through the TNF $\alpha$ activated HUVEC monolayer $(61.3 \pm 44.6$ migrated monocytes per microscopic field) compared to the MCP-1 (Figure 6C). Non TNF $\alpha$ activated HUVEC treated with MP were used to examine whether MP could induce monocyte transmigration under non-inflammatory conditions. The addition of MCP-1 did not induce an increase in transmigrated monocytes $(18.2 \pm 3,4$ migrated monocytes per microscopic field) compared to PBS (11 \pm 5.2 migrated monocytes per microscopic field). The number of transmigrated monocytes in the MP treated HUVEC was similar to the Non-treated HUVEC (15.3 \pm 7.1 migrated monocytes per microscopic field). The number of monocytes that migrated through the Non-Stimulated HUVEC monolayer was very low compared to TNF $\alpha$-Stimulated HUVEC and the number of monocytes that adhered to the Non-Stimulated HUVEC was also very low (Figure 6C).

\section{MP Increase Endothelial Monolayer Integrity}

To analyze whether MP induce a decrease in endothelial intercellular permeability, HUVEC were cultivated as tight monolayers in a transwell system and were treated or not with TNF $\alpha$, and two ratios of MP $(1: 50,000 ; 1: 100,000)$ during $24 \mathrm{~h}$. Thereafter, permeability was determined by measuring the passage of FITC-Dextran (molecular mass: $70 \mathrm{kDa}$ ) across HUVEC monolayers (Figure 7A). Results were normalized to the Non-Stimulated HUVEC control group. The analysis showed that both doses of MP decreased the endothelial permeability in Non-Stimulated HUVEC. TNF $\alpha$ stimulation induced a 2 -fold increase in the permeability of the monolayer compared to the Non-Stimulated control. At a dose of 1:100,000 MP significantly decreased endothelial permeability (Figure 7B).

\section{MP Have Pro-Angiogenic Properties}

The pro-angiogenic potential of MP on non-stimulated and TNF $\alpha$ stimulated HUVEC was determined by measuring four parameters (total tube length, total branching points, total loops, and covered area) (Figure 8A) using the tube formation assay. The experiment was performed in both groups of HUVEC after $24 \mathrm{~h}$ of incubation with and without TNF $\alpha$ and with and without MP. MP enhanced the process of angiogenesis in Non-
A

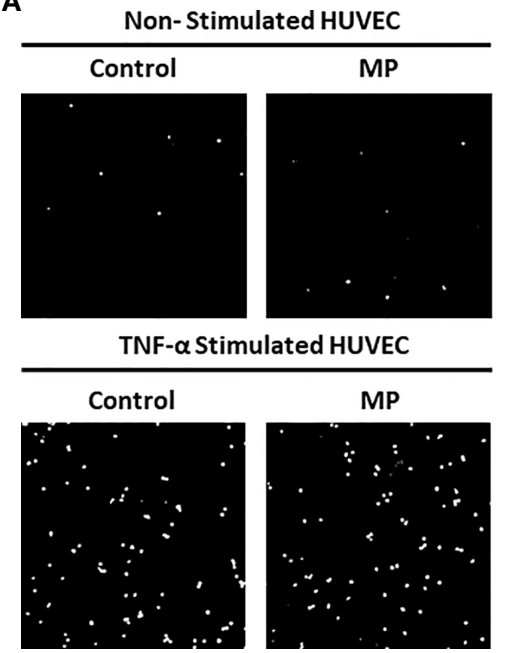

B

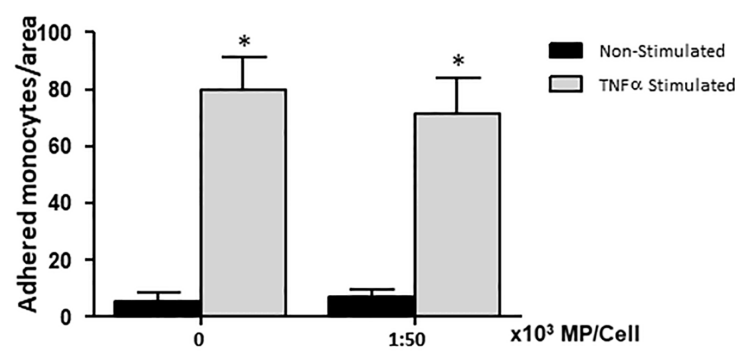

FIGURE 5 | Effects of Membrane Particles on monocyte adhesion to TNF $\alpha$-activated HUVEC. HUVEC were stimulated with TNF $\alpha$ and treated with MP at ratio 1:50,000. Subsequently, CFSE-labeled monocytes were added during 1h. (A) Representative fluorescent microscopy pictures show the adhered monocytes (white dots) to the HUVEC monolayer in non-stimulated and TNF $\alpha$ stimulated conditions. (B) Quantitative results of the monocyte adhesion assay analyzed by imageJ. No significance difference respect to the respective control (Non-Stimulated, and TNF $\alpha$ Stimulated HUVEC) was observed when MP were added * $\mathrm{p}<0.05$ compared to Non-Stimulated HUVEC. 
A

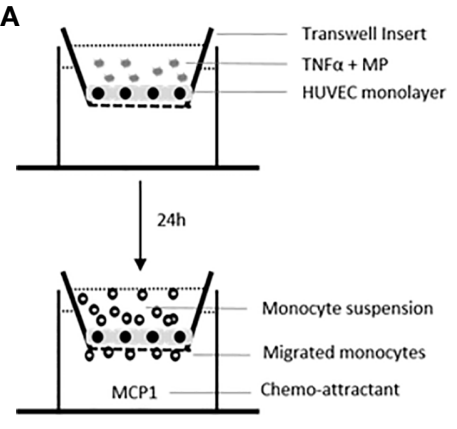

B

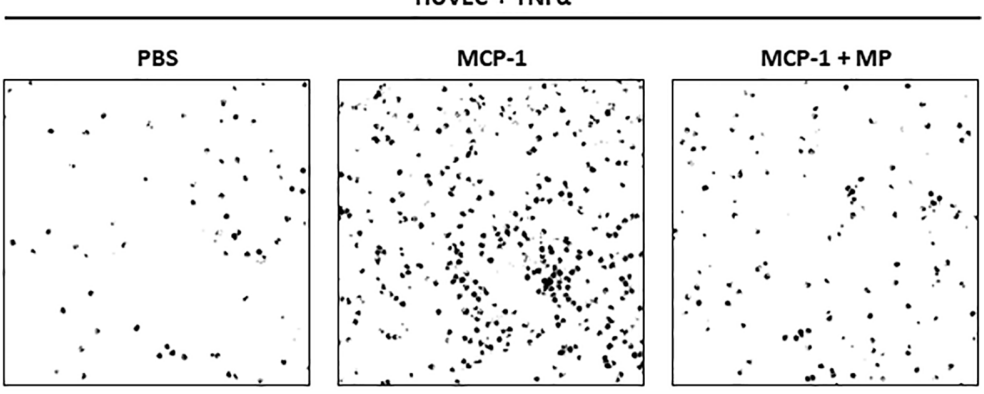

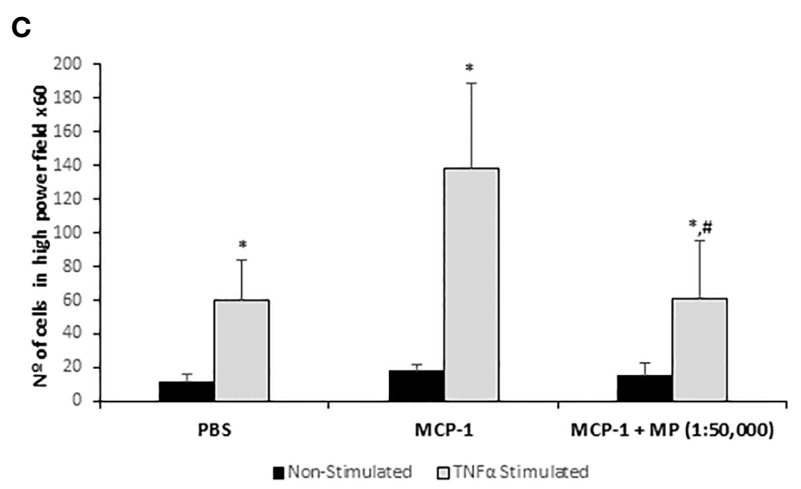

FIGURE 6 | Effect of Membrane Particles on migration of monocytes through a monolayer of TNF $\alpha$-activated HUVEC. (A) Schematic representation of the transmigration assay. HUVEC were seeded on transwell inserts until confluency. The monolayer of cells was treated with TNF $\alpha$ and 1:50,000 MP for $24 \mathrm{~h}$. Then, $1 \times 10^{5}$ isolated monocytes were added during $2 \mathrm{~h}$ with addition of the chemo-attractant MCP- 1 in the bottom well. Three pictures from randomly selected areas of the transwell were taken for the quantification. (B) Representative confocal microscopy images of the negative control (no MCP-1), positive control (MCP-1) and the MP treated group analyzed by ImageJ. (C) Quantitative results of the transmigration assay. Data represent means \pm SD of the number of transmigrated monocytes. ${ }^{*} \mathrm{p}<0.05$ respect to Non-Stimulated HUVEC. ${ }^{\#} \mathrm{p}<0.05$ respect to TNF $\alpha$ stimulated HUVEC non treated with MP in the MCP-1 group.

A

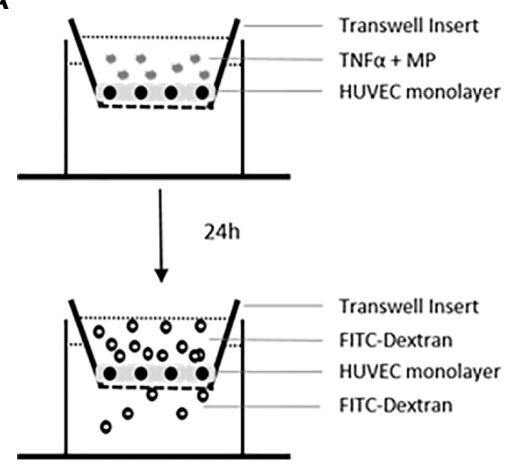

B

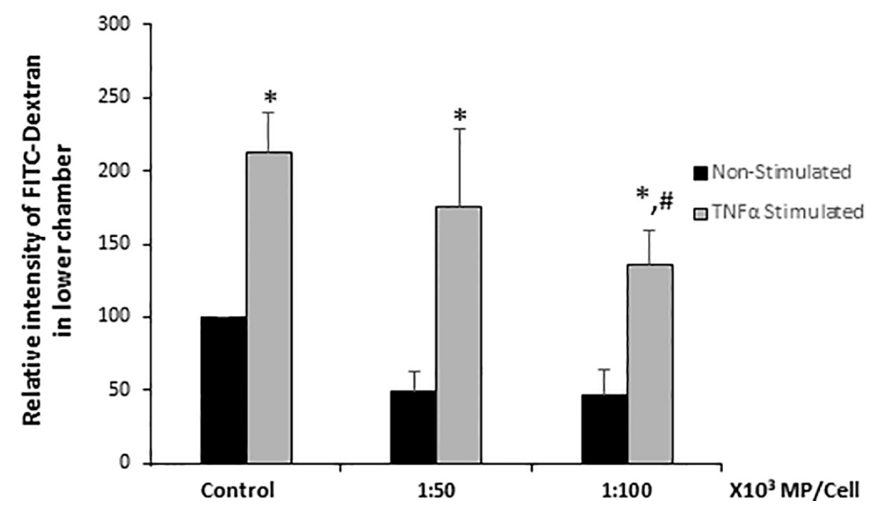

FIGURE 7 | HUVEC barrier integrity. (A) Schematic representation of the endothelial barrier model used in the study. HUVEC were seeded on transwell inserts until confluency and then treated with TNF $\alpha$ and MP $(1: 50,000$ and 1:100,000) during 24h. FITC-dextran was added during $2 \mathrm{~h}$, after which the fluorescence intensity in the lower chamber of the transwell system was quantified. (B) Quantitative results of the HUVEC barrier integrity assay. Data represent means \pm SD of 3 experiments using MP from 5 different donors. ${ }^{*} p<0.05$ compared with the respective control (Non-Stimulated HUVEC). ${ }^{*} p<0.05$ respect to TNF $\alpha$ stimulated HUVEC (Control).

Stimulated and TNF $\alpha$ Stimulated HUVEC with respect to their control groups (Figure 8B). The quantification of the angiogenesis parameters revealed a significant increase in total tube length, total branching points, total loops, and covered area for MP in Non-Stimulated HUVEC, and TNF $\alpha$ Stimulated HUVEC (Figure 8C). 
A

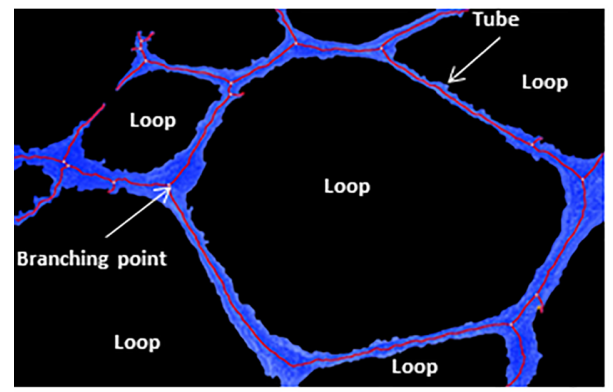

C
B
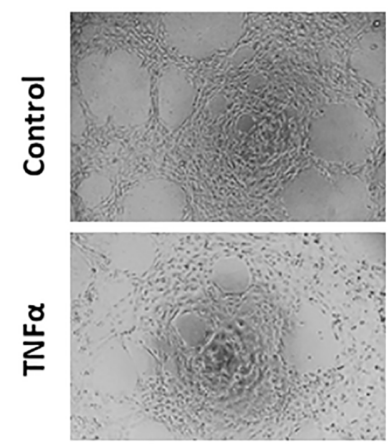

MP
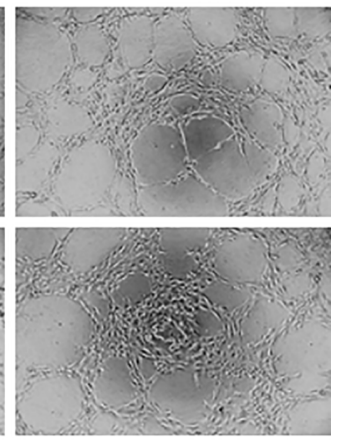
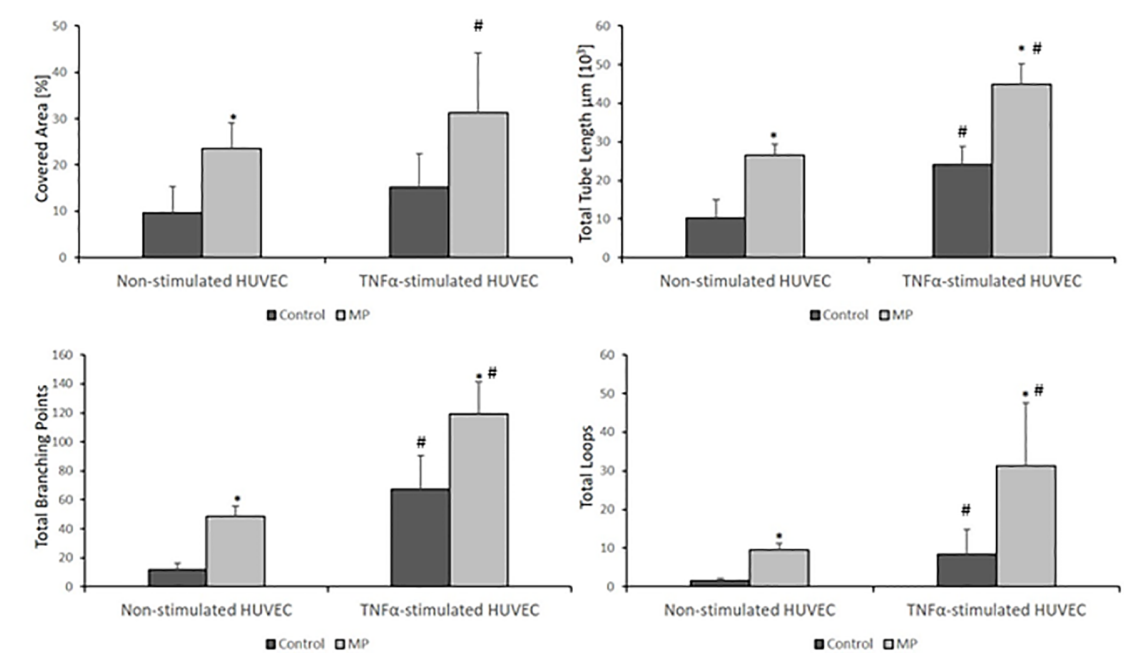

FIGURE 8 | MP induce angiogenesis in Non- and TNF $\alpha$ Stimulated conditions. (A) Analysis and identification of angiogenic features. (B) Angiogenesis assay images of Non-Stimulated and TNF $\alpha$ stimulated HUVEC under MP treatment. Quantitative image analysis of four angiogenic features (covered area (Blue lines), total tube length, total branching points, and the number of loops) in (C) Non-stimulated HUVEC, and TNF $\alpha$ stimulated HUVEC. The analysis was performed by the company WIMASIS. ${ }^{*} p<0.05$ compared with the control (no MP). ${ }^{*} p<0.05$ respect to Non-Stimulated HUVEC.

\section{DISCUSSION}

The present study demonstrates that small circular fragments of cell membranes from AT-MSC can ameliorate TNF $\alpha$ induced endothelial injury by improving endothelial cell monolayer integrity and enhancing their angiogenic capacity. MP encompass the surface molecules of MSC plasma membranes and contain RNA present in the mother cells, thereby exploiting some of the natural immunomodulatory and regenerative properties of MSC.

The generation of MP as a cell free cell-therapy emerged after our study to heat inactivated MSC (HI-MSC) where we observed that HI-MSC possessed immunomodulatory properties in vitro and in vivo, even being dead (14). HI-MSC lost the capacity to secrete factors, or any another function related to the living cells such as proliferation, while keeping the cell membrane intact. This suggests that MSC membranes with their associated proteins can govern at least some of the effects of MSC. The size of HI-MSC is similar as MSC and HI-MSC get trapped in the lung capillary system after their administration (14). To retain the biological properties of MSC and concomitantly overcome the problems of living cells, the generation of MSC membranes in the nano-range devoid of cytoplasm and nucleus represent a new promising approach in the cell therapy field and is supported by the EV studies $(22,23)$.

MP and EV derived from MSC provide several advantages over MSC. Both types of nanoparticles cannot be modified by the molecular environment after their administration as they are a fixed representation of MSC. Similar to naturally occurring EV, the small size of MP $(<200 \mathrm{~nm})$ makes them more suitable for crossing the lung barrier than $\operatorname{MSC}(24,25)$ and due to a better biodistribution can exert broadly their effects in the organism (26).

Interestingly, mRNA for factors such as VEGF, IL-8, and CD90 from the MSC were detected in MP. It is assumable that these mRNAs are on the inside of the MP as RNAases would 
likely degrade free floating RNA. The relative gene expression of these factors in MP samples was different between donors and may be related to the inherent donor variation or to differences in the grade of RNA degradation during the process of MP generation. To minimize the impact on the results due the different amount of mRNA between samples, several batches of MP per donor were used to perform the experiments. One of the mechanisms proposed for explaining the action of EV is the transfer of RNA to the target cells $(27,28)$. Whether this mechanism is also occurring with MP deserves further studies.

To evaluate whether MP is a potential treatment to repair inflamed endothelium, several aspects of endothelial repair were studied. We showed that MP were efficiently taken up by HUVEC, and that their last destination are the lysosomes of the cells. Recently, we have studied the mechanisms of MP internalization (29). Specific inhibitors for endocytic pathways revealed that MP internalization depends on heparan sulfate proteoglycan-, dynamin-, and clathrin-mediated endocytosis but does not involve caveolin-mediated endocytosis. MP uptake also involved the actin cytoskeleton and phosphoinositide 3-kinase, which are implicated in macropinocytosis and phagocytosis. Due to the different pathways involved in the uptake of MP, the mechanisms involved in their actions may be very different. Several authors described that endocytosis is the most common pathway used by cells to incorporate natural vesicles such as exosomes, and microvesicles to their cytoplasma $(30,31)$. Bhagyashree S. Joshi et al. (32) demonstrated that EV are internalized by endocytosis and phagocytosis as MP, and the internalized EV fuse with the limiting membrane of endosomes and lysosomes in an acidification-dependent manner, which results in EV cargo exposure to the cell cytosol. MP may be processed by the cells in a similar manner, but future studies should address this question.

Potential adverse effects such as cytotoxicity and upregulation of adhesion molecules on HUVEC by MP were analyzed. No increase in apoptotic HUVEC was observed even with the highest concentration of MP in the inflammatory condition. MP did not have any role on the modulation of the surface adhesion molecules of HUVEC. It is important to highlight that MP did not induce the activation of the HUVEC under normal conditions, which makes them a safe treatment for EC. Because MP did not downregulate the expression of surface adhesion molecules on HUVEC under inflammatory conditions, the adhesion of the monocytes to the activated EC could not be suppressed. Several studies have described the relation of EC adhesion markers and monocyte adhesion. Blocking ICAM-1 receptors (33) in EC, or downregulating the expression of adhesion receptors in EC with molecules such as L-Arginine (34), and Eicosapentaenoic Acid (35) was correlated with a decrease of monocyte adhesion. Although MP did not decrease the number of monocytes adhered to EC, MP were able to prevent the migration of monocytes through a monolayer of HUVEC. Several authors described that MSC inhibit the recruitment of leukocytes $(9,36)$, but there are some doubts about the mechanisms of action. MSC could physically obstruct the transmigration of leukocytes (37), or immune cells could interact adhesively with MSC thereby reducing the number of cells available to bind to EC (38). MP cannot physically block the migration of monocytes through the barrier of EC, and furthermore in our experiments, MP were removed before the addition of the leukocytes, so they could not interact with the leukocytes themselves. The most likely mechanism explaining the impeding of monocyte transmigration by MP is that MP restore the HUVEC barrier integrity from TNF $\alpha$-induced leakiness by stimulating a more compact HUVEC monolayer structure. This characteristic of MP is shared with MSC and EV derived from MSC $(39,40)$.

Additionally, we showed that MP stimulate the angiogenic potential of HUVEC in normal and inflammatory conditions. This effect has also been reported for EV derived from MSC (41), and the described mechanism is through the transfer of miRNAs from EV to the recipient cells (42). It is possible that MP share this mechanism of action with EV as MP also contain mRNAs involved in angiogenesis such as VEGF, angiopoietin 1.

These features of MP, blocking of transmigration, restoring endothelium integrity, and stimulation of angiogenesis could be used in the treatment of different vascular complications such as atherosclerosis, infiltration of immune cells in organ rejection, in the joins in rheumatoid arthritis, or for injured endothelium after organ ischemia. In comparison with similar treatments such as MSC or EV derived from MSC, MP offer the advantage of their small size, purity and excellent safety profile and the possibility for upscaling production in a controlled manner.

In conclusion, MP show a promising medicinal potential, opening a new avenue for treatment of vascular diseases where the inflammatory process is involved in the damage of the endothelium.

\section{DATA AVAILABILITY STATEMENT}

The raw data supporting the conclusions of this article will be made available by the authors, without undue reservation.

\section{ETHICS STATEMENT}

The tissues were collected after obtaining written informed consent, as approved by the Medical Ethical Committee of the Erasmus University Medical Centre Rotterdam (protocol no. MEC-2006-190).

\section{AUTHOR CONTRIBUTIONS}

$\mathrm{AM}$ and $\mathrm{MH}$ designed the study. AM, SK, and MS performed the research. $\mathrm{AM}, \mathrm{MH}, \mathrm{CL}-\mathrm{I}$, and $\mathrm{CB}$ participated in the interpretation of the data. AM wrote the paper. $\mathrm{MO}-\mathrm{V}, \mathrm{CB}$, $\mathrm{EL}$, and $\mathrm{MH}$ wrote the manuscript (review and editing). All authors contributed to the article and approved the submitted version. 


\section{ACKNOWLEDGMENTS}

This collaboration project is co-funded by the PPP Allowance made available by Health Holland, Top Sector Life Sciences \&

\section{REFERENCES}

1. Marchio P, Guerra-Ojeda S, Vila JM, Aldasoro M, Victor VM, Mauricio MD. Targeting Early Atherosclerosis: A Focus on Oxidative Stress and Inflammation. Oxid Med Cell Longev (2019) 2019:8563845. doi: 10.1155/ 2019/8563845

2. Li X, Xiao H, Lin C, Sun W, Wu T, Wang J, et al. Synergistic effects of liposomes encapsulating atorvastatin calcium and curcumin and targeting dysfunctional endothelial cells in reducing atherosclerosis. Int J Nanomed (2019) 14:649-65. doi: 10.2147/IJN.S189819

3. Yong YX, Yang H, Lian J, Xu XW, Han K, Hu MY, et al. Up-regulated microRNA-199b-3p represses the apoptosis of cerebral microvascular endothelial cells in ischemic stroke through down-regulation of MAPK/ ERK/EGR1 axis. Cell Cycle (2019) 18(16):1868-81. doi: 10.1080/ 15384101.2019.1632133

4. Yang O, Li J, Kong J. The Endothelium as a Target for the Treatment of Heart Failure. Cell Biochem Biophys (2015) 72(3):751-6. doi: 10.1007/s12013-0150526-7

5. Goligorsky MS. Vascular endothelium in diabetes. Am J Physiol Renal Physiol (2017) 312(2):F266-75. doi: 10.1152/ajprenal.00473.2016

6. Wang S, Zhang C, Wang J, Yang C, Xu M, Rong R, et al. Endothelial Cells in Antibody-Mediated Rejection of Kidney Transplantation: Pathogenesis Mechanisms and Therapeutic Implications. J Immunol Res (2017) 2017:8746303. doi: 10.1155/2017/8746303

7. Nelson AJ, Dundon BK, Worthley SG, Richardson JD, Puri R, Wong DTL, et al. End-stage renal failure is associated with impaired coronary microvascular function. Coron Artery Dis (2019) 30(7):520-7. doi: 10.1097/ MCA.0000000000000727

8. Kolaczkowska E, Kubes P. Neutrophil recruitment and function in health and inflammation. Nat Rev Immunol (2013) 13(3):159-75. doi: 10.1038/nri3399

9. Munir H, Luu NT, Clarke LS, Nash GB, McGettrick HM. Comparative Ability of Mesenchymal Stromal Cells from Different Tissues to Limit Neutrophil Recruitment to Inflamed Endothelium. PloS One (2016) 11(5):e155161. doi: 10.1371/journal.pone.0155161. eCollection 2016.

10. Wei X, Sun G, Zhao X, Wu Q, Chen L, Xu Y, et al. Human amnion mesenchymal stem cells attenuate atherosclerosis by modulating macrophage function to reduce immune response. Int J Mol Med (2019)44 (4):1425-35. doi: 10.3892/ijmm.2019.4286

11. Steiner D, Köhn K, Beier JP, Stürzl M, Horch RE, Arkudas A. Cocultivation of Mesenchymal Stem Cells and Endothelial Progenitor Cells Reveals Antiapoptotic and Proangiogenic Effects. Cells Tissues Organs (2017) 204(5-6): 218-27. doi: 10.1159/000478654

12. Eggenhofer E, Benseler V, Kroemer A, Popp FC, Geissler EK, Schlitt HJ, et al. Mesenchymal stem cells are short-lived and do not migrate beyond the lungs after intravenous infusion. FrontImmunol (2012) 3:297. doi: 10.3389/ fimmu.2012.00297

13. Agrawal H, Shang H, Sattah AP, Yang N, Peirce SM, Katz AJ, et al. Human adipose-derived stromal/stem cells demonstrate short-lived persistence after implantation in both an immunocompetent and an immunocompromised murine model. Stem Cell Res Ther (2014) 5:142. doi: 10.1186/scrt532

14. Luk F, de Witte SF, Korevaar SS, Roemeling-van Rhijn M, Franquesa M, Strini $\mathrm{T}$, et al. Inactivated Mesenchymal Stem Cells Maintain Immunomodulatory Capacity. Stem Cells Dev (2016) 25(18):1342-54. doi: 10.1089/scd.2016.0068

15. Aryan A, Bayat M, Bonakdar S, Taheri S, Haghparast N, Bagheri M, et al. Human Bone Marrow Mesenchymal Stem Cell Conditioned Medium Promotes Wound Healing in Deep Second-Degree Burns in Male Rats. Cells Tissues Organs (2019) 24:1-13. doi: 10.1159/000501651

16. Doyle LM, Wang MZ. Overview of Extracellular Vesicles, Their Origin, Composition, Purpose, and Methods for Exosome Isolation and Analysis. Cells (2019) 8(7):pii: E727. doi: 10.3390/cells8070727

17. Ju C, Shen Y, Ma G, Liu Y, Cai J, Kim IM, et al. Transplantation of Cardiac Mesenchymal Stem Cell-Derived Exosomes Promotes Repair in Ischemic
Health, of the Dutch Ministry of Economic affairs to stimulate public-private partnerships. We thank Hans Duimel, electron microscopy specialist del Microscopy CORE Lab, M4I, Maastricht University, for his technical support.

Myocardium. J Cardiovasc Transl Res (2018) 11(5):420-8. doi: 10.1007/ s12265-018-9822-0

18. Bruno S, Tapparo M, Collino F, Chiabotto G, Deregibus MC, Soares Lindoso R, et al. Renal Regenerative Potential of Different Extracellular Vesicle Populations Derived from Bone Marrow Mesenchymal Stromal Cells. Tissue Eng Part A (2017) 23(21-22):1262-73. doi: 10.1089/ten.TEA.2017.0069

19. Franquesa M, Hoogduijn MJ, Ripoll E, Luk F, Salih M, Betjes MG, et al. Update on controls for isolation and quantification methodology of extracellular vesicles derived from adipose tissue mesenchymal stem cells. Front Immunol (2014) 5:525. doi: 10.3389/fimmu.2014.00525

20. Abramowicz A, Widlak P, Pietrowska M. Proteomic analysis of exosomal cargo: the challenge of high purity vesicle isolation. Mol Biosyst (2016) 12 (5):1407-19. doi: 10.1039/c6mb00082g

21. Gonçalves FDC, Luk F, Korevaar SS, Bouzid R, Paz AH, López-Iglesias C, et al. Membrane particles generated from mesenchymal stromal cells modulate immune responses by selective targeting of pro-inflammatory monocytes. Sci $\operatorname{Rep~(2017)~7(1):12100.~doi:~10.1038/s41598-017-12121-z~}$

22. EL Andaloussi S, Mäger I, Breakefield XO, Wood MJA. Extracellular vesicles: biology and emerging therapeutic opportunities. Nat Rev Drug Discovery (2013) 12:347-57. doi: 10.1038/nrd3978

23. Wiklander OPB, Brennan MÁ, Lötvall J, Breakefield XO, EL Andaloussi S. Advances in therapeutic applications of extracellular vesicles. Sci Trans Med (2019) 11(492):eaav8521. doi: 10.1126/scitranslmed.aav8521

24. Lai CP, Mardini O, Ericsson M, Prabhakar S, Maguire C, Chen JW, et al. Dynamic biodistribution of extracellular vesicles in vivo using a multimodal imaging reporter. ACS Nano (2014) 8(1):483-94. doi: 10.1021/ nn404945r

25. Moon GJ, Sung JH, Kim DH, Kim EH, Cho YH, Son JP, et al. Application of Mesenchymal Stem Cell-Derived Extracellular Vesicles for Stroke: Biodistribution and MicroRNA Study. Transl Stroke Res (2019) 10(5):50921. doi: 10.1007/s12975-018-0668-1

26. Grange C, Tapparo M, Bruno S, Chatterjee D, Quesenberry PJ, Tetta C, et al. Biodistribution of mesenchymal stem cell-derived extracellular vesicles in a model of acute kidney injury monitored by optical imaging. Int J Mol Med (2014) 33(5):1055-63. doi: 10.3892/ijmm.2014.1663

27. van der Vos KE, Abels ER, Zhang X, Lai C, Carrizosa E, Oakley D, et al. Directly visualized glioblastoma-derived extracellular vesicles transfer RNA to microglia/macrophages in the brain. Neuro-Oncology (2016) 18(1):58-69. doi: $10.1093 /$ neuonc/nov244

28. O’Brien K, Breyne K, Ughetto S, Laurent LC, Breakefield XO. RNA delivery by extracellular vesicles in mammalian cells and its applications. Nat Rev Mol Cell Biol (2020) 21:585-606. doi: 10.1038/s41580-020-0251-y

29. Da Costa Gonçalves F, Korevaar SS, Ortiz Virumbrales M, Baan CC, Reinders MEJ, Ana M, et al. Mesenchymal Stromal Cell Derived Membrane Particles Are Internalized by Macrophages and Endothelial Cells Through ReceptorMediated Endocytosis and Phagocytosis. Front Immunol (2021) 12:651109. doi: 10.3389/fimmu.2021.651109

30. Mulcahy LA, Pink RC, Carter DR. Routes and mechanisms of extracellular vesicle uptake. J Extracell Vesicles (2014) 4:3. doi: 10.3402/jev.v3.24641. eCollection 2014. Review.

31. Tian T, Zhu YL, Zhou YY, Liang GF, Wang YY, Hu FH, et al. Exosome uptake through clathrin-mediated endocytosis and macropinocytosis and mediating miR-21 delivery. J Biol Chem (2014) 289(32):22258-67. doi: 10.1074/ jbc.M114.588046

32. Joshi BS, de Beer MA, Giepmans BNG, Zuhorn IS. Endocytosis of Extracellular Vesicles and Release of Their Cargo from Endosomes. ACS Nano (2020) 14(4):4444-55. doi: 10.1021/acsnano.9b10033

33. Kevil CG, Patel RP, Bullard DC. Essential role of ICAM-1 in mediating monocyte adhesion to aortic endothelial cells. Am J Physiol Cell Physiol (2001) 281(5):C1442-7. doi: 10.1152/ajpcell.2001.281.5.C1442

34. Adams MR, Jessup W, Hailstones D, Celermajer DS. L-arginine reduces human monocyte adhesion to vascular endothelium and endothelial 
expression of cell adhesion molecules. Circulation (1997) 95(3):662-8. doi: 10.1161/01.cir.95.3.662

35. Yamada H, Yoshida M, Nakano Y, Suganami T, Satoh N, Mita T, et al. In vivo and in vitro inhibition of monocyte adhesion to endothelial cells and endothelial adhesion molecules by eicosapentaenoic acid. Arterioscler Thromb Vasc Biol (2008) 28(12):2173-9. doi: 10.1161/ATVBAHA.108.171736

36. Luu NT, McGettrick HM, Buckley CD, Newsome PN, Rainger GE, Frampton $\mathrm{J}$, et al. Crosstalk between mesenchymal stem cells and endothelial cells leads to downregulation of cytokine-induced leukocyte recruitment. Stem Cells (2013) 31(12):2690-702. doi: 10.1002/stem.1511

37. Chamberlain G, Smith H, Rainger GE, Middleton J. Mesenchymal stem cells exhibit firm adhesion, crawling, spreading and transmigration across aortic endothelial cells: effects of chemokines and shear. PloS One (2011) 6(9): e25663. doi: 10.1371/journal.pone.0025663

38. de Witte SFH, Luk F, Sierra Parraga JM, Gargesha M, Merino A, Korevaar SS, et al. Immunomodulation by Therapeutic Mesenchymal Stromal Cells (MSC) Is Triggered Through Phagocytosis of MSC By Monocytic Cells. Stem Cells (2018) 36(4):602-15. doi: 10.1002/stem.2779

39. Chen QH, Liu AR, Qiu HB, Yang Y. Interaction between mesenchymal stem cells and endothelial cells restores endothelial permeability via paracrine hepatocyte growth factor in vitro. Stem Cell Res Ther (2015) 6:44. doi: 10.1186/s13287-015-0025-1

40. Potter DR, Miyazawa BY, Gibb SL, Deng X, Togaratti PP, Croze RH, et al. Mesenchymal stem cell-derived extracellular vesicles attenuate pulmonary vascular permeability and lung injury induced by hemorrhagic shock and trauma. J Trauma Acute Care Surg (2018) 84(2):245-56. doi: 10.1097/ TA.0000000000001744

41. Shi Y, Shi H, Nomi A, Lei-Lei Z, Zhang B, Qian H. Mesenchymal stem cell-derived extracellular vesicles: a new impetus of promoting angiogenesis in tissue regeneration. Cytotherapy (2019) 21(5):497-508. doi: 10.1016/j.jcyt.2018.11.012

42. Ma T, Chen Y, Chen Y, Meng Q, Sun J, Shao L, et al. MicroRNA-132, Delivered by Mesenchymal Stem Cell-Derived Exosomes, Promote Angiogenesis in Myocardial Infarction. Stem Cells Int (2018) 2018:3290372. doi: $10.1155 / 2018 / 3290372$

Conflict of Interest: Erasmus MC filed a patent on the use of MP for immunomodulatory purposes. Authors MO-V and EL were employed by Takeda Madrid.

The remaining authors declare that the research was conducted in the absence of any commercial or financial relationships that could be constructed as a potential conflict of interest.

Copyright $\odot 2021$ Merino, Sablik, Korevaar, López-Iglesias, Ortiz-Virumbrales, Baan, Lombardo and Hoogduijn. This is an open-access article distributed under the terms of the Creative Commons Attribution License (CC BY). The use, distribution or reproduction in other forums is permitted, provided the original author(s) and the copyright owner(s) are credited and that the original publication in this journal is cited, in accordance with accepted academic practice. No use, distribution or reproduction is permitted which does not comply with these terms. 